\title{
Insulin-like growth factor I is expressed in classical and nodular lymphocyte-predominant Hodgkin's lymphoma tumour and microenvironmental cells
}

\author{
Eppler, Elisabeth ; Janas, Eva ; Link, Karl ; Weidmann, Lukas ; Bischofberger, Helena ; Wenger, \\ Michael ; Tinguely, Marianne ; Schraml, Peter ; Moch, Holger ; Fellbaum, Christian
}

\begin{abstract}
Hodgkin's lymphoma (HL) is among the most frequent nodal lymphomas in the Western world and is classified into two disease entities: nodular lymphocyte-predominant Hodgkin's lymphoma (NLPHL) and classical Hodgkin's lymphoma (cHL, $95 \%$ of all HL). HL lesions are characterised by a minority of clonal neoplastic cells, namely Hodgkin and Reed-Sternberg (HRS) cells and their variants in cHL and lymphocyte-predominant (LP) cells in NLPHL, both occurring within a microenvironment of, for example, reactive $\mathrm{T}$ and $\mathrm{B}$ cells, macrophages and granulocytes that are assumed to support the proliferation and maintenance of neoplastic cells through cytokines, chemokines and growth factors. Insulin-like growth factor I (IGF-I) is an important growth factor involved in proliferation, differentiation, apoptosis and cell survival of numerous (including immune) tissues and probably has a role in tumour pathogenesis and maintenance. Although HL is characterised by disturbed cell differentiation and apoptosis mechanisms, with the involvement of the IGF-I receptor (IGF-1R), the distinct location of IGF-I in HL has not yet been defined. We localise IGF-I by double-immunofluorescence in frequent neoplastic cells of all cHL and NLPHL cases investigated. Additionally, IGF-I immunoreactivity is detected in high endothelial venules and various immune cells within the surrounding tissue of cHL including neutrophils and macrophages. IGF-1R immunoreactivity of variable intensity is found in HRS cells and high endothelial venules within the microenvironment in cHL. We assume that autocrine and paracrine IGF-I plays an anti-apoptotic role in tumour pathogenesis and in shaping the tumour microenvironment.
\end{abstract}

DOI: https://doi.org/10.1007/s00441-014-2052-0

Posted at the Zurich Open Repository and Archive, University of Zurich

ZORA URL: https://doi.org/10.5167/uzh-102973

Journal Article

Published Version

Originally published at:

Eppler, Elisabeth; Janas, Eva; Link, Karl; Weidmann, Lukas; Bischofberger, Helena; Wenger, Michael; Tinguely, Marianne; Schraml, Peter; Moch, Holger; Fellbaum, Christian (2015). Insulin-like growth factor I is expressed in classical and nodular lymphocyte-predominant Hodgkin's lymphoma tumour and microenvironmental cells. Cell and Tissue Research, 359(3):841-851.

DOI: https://doi.org/10.1007/s00441-014-2052-0 


\title{
Insulin-like growth factor $I$ is expressed in classical and nodular lymphocyte-predominant Hodgkin's lymphoma tumour and microenvironmental cells
}

\author{
Elisabeth Eppler • Eva Janas • Karl Link • Lukas Weidmann • \\ Helena Bischofberger • Michael Wenger • Marianne Tinguely • \\ Peter Schraml • Holger Moch • Christian Fellbaum
}

Received: 31 January 2014 / Accepted: 27 October 2014 /Published online: 9 December 2014

(C) Springer-Verlag Berlin Heidelberg 2014

\begin{abstract}
Hodgkin's lymphoma (HL) is among the most frequent nodal lymphomas in the Western world and is classified into two disease entities: nodular lymphocyte-predominant Hodgkin's lymphoma (NLPHL) and classical Hodgkin's lymphoma (cHL, $95 \%$ of all HL). HL lesions are characterised by a minority of clonal neoplastic cells, namely Hodgkin and Reed-Sternberg (HRS) cells and their variants in cHL and lymphocyte-predominant (LP) cells in NLPHL, both occurring within a microenvironment of, for example, reactive $\mathrm{T}$ and $\mathrm{B}$ cells, macrophages and granulocytes that are assumed to support the proliferation and maintenance of neoplastic cells through cytokines, chemokines and growth factors.
\end{abstract}

This study was supported by the Foundation for Scientific Research at the University of Zürich/Baugarten Stiftung, by the Kurt and Senta Herrmann-Foundation and by the Prof. Dr. med. Karl and Rena TheilerHaag-Foundation.

E. Eppler $(\bowtie) \cdot$ E. Janas $\cdot$ K. Link $\cdot$ L. Weidmann •

$\mathrm{H}$. Bischofberger $\cdot \mathrm{M}$. Wenger

Research Group Neuro-endocrine-immune Interactions, Institute of Anatomy, University of Zurich, Zurich, Switzerland

e-mail: elisabeth.eppler@uzh.ch

E. Eppler

Zurich Center for Integrative Human Physiology (ZIHP), University

of Zurich, Zurich, Switzerland

E. Eppler

Institute of Neuroradiology, University Hospital,

Otto-von-Guericke-University, Magdeburg, Germany

M. Tinguely $\cdot$ P. Schraml $\cdot$ H. Moch

Institute of Surgical Pathology, University Hospital Zurich, Zurich,

Switzerland

M. Tinguely

Kempf and Pfaltz, Histologische Diagnostik, Zurich, Switzerland

C. Fellbaum

Institute of Pathology, Hegau-Bodensee Clinic, Singen, Germany
Insulin-like growth factor I (IGF-I) is an important growth factor involved in proliferation, differentiation, apoptosis and cell survival of numerous (including immune) tissues and probably has a role in tumour pathogenesis and maintenance. Although HL is characterised by disturbed cell differentiation and apoptosis mechanisms, with the involvement of the IGF-I receptor (IGF-1R), the distinct location of IGF-I in HL has not yet been defined. We localise IGF-I by doubleimmunofluorescence in frequent neoplastic cells of all cHL and NLPHL cases investigated. Additionally, IGF-I immunoreactivity is detected in high endothelial venules and various immune cells within the surrounding tissue of $\mathrm{cHL}$ including neutrophils and macrophages. IGF-1R immunoreactivity of variable intensity is found in HRS cells and high endothelial venules within the microenvironment in $\mathrm{cHL}$. We assume that autocrine and paracrine IGF-I plays an anti-apoptotic role in tumour pathogenesis and in shaping the tumour microenvironment.

Keywords IGF-I · IGF-1R · Growth factors · Hodgkin's disease $\cdot$ Reed-Sternberg cells $\cdot$ LP cells $\cdot$ Immune cells

\section{Introduction}

Hodgkin's lymphoma (HL) is one of the most frequent nodal lymphomas in the Western world (Roman and Smith 2011). Current treatment protocols involving multi-agent chemotherapy and/or radiotherapy achieve cure rates of $80-90 \%$ (for a review, see Küppers 2009) but approximately $40 \%$ of patients are refractory to initial treatment or relapse after complete remission.

HL represents a special group of malignancies, because only about $0.5-2 \%$ of the tumour mass is composed of tumour cells, whereas the majority of cells within HL lesions 
are an infiltrate of various cell types of the immune system. Classical HL (cHL) lesions are characterised by Hodgkin and Reed-Sternberg (HRS) cells residing in a mixture of reactive cells (T and B cells, macrophages, plasma cells, granulocytes), which are thought to support the proliferation of HRS cells and the reactive cells within the tumour background through cytokines and chemokines (Schmitz et al. 2009; Renné et al. 2009; Farrell and Jarrett 2011; Küppers et al. 2011). Important progress has recently been made revealing the pathogenesis of cHL; the tumour cells are assumed to be derived from germinal centre B cells that have acquired disadvantageous mutations in the immunoglobulin Ig variable chain gene ("crippled mutation"), which should have undergone apoptosis but that circumvent apoptotic cell death (Kanzler et al. 1996). In nodular lymphocyte-predominant HL (NLPHL), the neoplastic tumour cells are the lymphocyte-predominant (LP) cells. Whereas LP cells still strongly express CD20 as a marker, which is predominantly expressed by human B cells, HRS cells in cHL have mainly lost the expression patterns of physiological B cells and preferentially express the tumour necrosis factor (TNF) receptor family marker CD30 (Schwering et al. 2003; Steimle-Grauer et al. 2003; Swerdlow et al. 2008; Küppers et al. 2011).

HRS cells attract numerous cells into or in the lymphatic tissue, resulting in an inflammatory microenvironment that probably promotes their survival. An aberrant immune response in the vicinity of HRS cells seems to maintain an immunosuppressive environment (Chetaille et al. 2009), e.g., by the attraction of anergic $\mathrm{T}$ cells that suppress a cytotoxic anti-tumour response (Küppers 2009). Since HRS cells, in the overwhelming majority of cases, are neoplastic B cells, the cytokines that are produced by these T cells might even assist HRS cell growth and survival. Further exploration of cytokines and growth factors involved in chemoattraction, proliferation, differentiation, organ composition and sustainment and in pro- and anti-inflammatory regulation is therefore needed to improve our understanding not only of the complexity of HL pathogenesis but also of the general mechanisms of tumour escape.

Insulin-like growth factor I (IGF-I) is a pleiotropic growth factor involved in the regulation of proliferation, differentiation, protection against apoptosis and cell survival. IGF-I is produced not only in the liver with growth hormone $(\mathrm{GH})$ as a major stimulus for its synthesis and release (termed the endocrine route) but also in extrahepatic sites where it is thought to exert autocrine and paracrine effects via the IGF-I receptor (IGF-1R), a tetrameric tyrosine receptor kinase that is under investigation for cancer therapy (e.g., Okusaka et al. 2014; Gao et al. 2014). Previous work in cHL has revealed a role for tyrosine receptor kinases as potential therapeutic targets (Renné et al. 2005) and additional receptor-ligand interactions are being investigated in HL, such as the cannabinoid receptor (Benz et al. 2013).
A role for both IGF-I and its receptor in tumour proliferation and metastasis has been under debate for decades (Pollak 2009; Gallagher and LeRoith 2011; Clayton et al. 2011; Dijogue et al. 2013). For instance, a predisposing effect of $\mathrm{GH}$ overproduction in acromegaly for B cell diseases has been suggested in the light of a clinical case of thyroid cancer and follow-up non-HL attributed to elevated IGF-I levels (Taslipinar et al. 2009). Moreover, IGF-I has been proposed to regulate pro-B cell differentiation during which haematopoetic precursor cells (pro-B cells) initiate the rearrangement of Ig heavy chains, express $\mu$-heavy chain protein and subsequently rearrange and express Ig light chain products before they exit the bone marrow as immunocompetent $\mathrm{B}$ lymphocytes (Landreth et al. 1992). This rearrangement of Ig genes coincides with the initial expression of B220 in mice, an event that correlates with commitment to the B cell lineage. IGF-I protects human lymphocytes against apoptosis (AvilaGomez et al. 2009) indicating the potential role of IGF-I in the transition of apoptosis-evading B lymphocytes to HL cells. Most recently, IGF-I has been shown to specifically stimulate tumour cell growth in Hodgkin cell lines via the IGF-1R in vitro but HL patients expressing IGF-1R on cHL tumour cells demonstrate a better clinical outcome which supports a role of the IGF-I system in HL; however, the data are still contradictory (Liang et al. 2014). IGF-I has not as yet been localised within HL tissue. Nevertheless, knowledge of the presence of the ligand, be it within the tumour cells or within the microenvironment, might help to unravel the potential autocrine/paracrine role of the local IGF-I/IGF-1R axis for the pathogenesis of HL.

Thus, in the present study, we define the cellular sites of IGF-I in HL histopathological samples by doubleimmunofluorescence for IGF-I and the established markers (CD20, CD30) regularly expressed by the respective tumour cells. Furthermore, using specific markers (CD3, CD15, CD20, CD68), we identify IGF-I in specific cells of the microenvironment in cHL. Additionally, we confirm the presence of the IGF-1R in cHL cells as recently described (Liang et al. 2014) by immunohistochemistry on a histopathological tissue array.

\section{Materials and methods}

\section{Archival samples}

This study was approved by the official authorities of the ethical committee of the Canton Zürich (StV2-2007). Archival tissue samples were obtained by the tissue bank (accreditation no. STS 548) of the Institute of Surgical Pathology, University Hospital, Zurich. The tissue bank (Steu et al. 2008; von Teichman et al. 2012) fulfils the requirements of the International Society of Biological and Environmental Repositories 
(ISBER). The tissue bank sample contains $34 \mathrm{cHL}$ samples (13 mixed cellularity, 21 nodular sclerosis). Four additional samples ( 1 mixed cellularity type cHL, 3 NLPHL) from anonymised archival histopathological material were provided by the Institute of Pathology, Hegau-Bodensee Clinic, Singen. The diagnosis followed the criteria of the current WHO lymphoma classification (Swerdlow et al. 2008). For 34 patients, clinical data (gender, age at diagnosis) were known (21 male, 13 female patients between 13 and 83 years, average 42 years). No clinical data were available from 4 patients.

\section{Tissue preparation}

Lymph nodes were formalin-fixed and embedded into Paraplast. A tissue microarray (TMA) was constructed by taking duplicate cores of $650 \mu \mathrm{m}$ from each biopsy $(n=34)$ as described previously (Butsch et al. 2011; Soldini et al. 2013) and cut at a thickness of $2.5 \mu \mathrm{m}$. In addition, one mixed cellularity type cHL and three NLPHL cases were conventionally cut on a microtome (Mettler Toledo, Germany) at a thickness of $5 \mu \mathrm{m}$; consecutive sections were mounted on Super Frost Plus slides (Menzel-Gläser, Germany) and dried overnight at $42{ }^{\circ} \mathrm{C}$. Both tissue preparations were subjected to further morphological analysis after being dewaxed in Xylol and rehydration in a descending series of ethanol $(100,96,80$, $70 \%$, all reagents obtained from Fluka, Switzerland). The quality of the sampled area and the presence of neoplastic follicles were ascertained by haematoxylin and eosin (HE) staining.

\section{Double-immunofluorescence}

Double-immunofluorescence for IGF-I with CD markers was performed as previously established for human lymph nodes (Oberlin et al. 2009) with the modification that for cHL CD30, for NLPHL CD20, and for granulocytes CD15 (all DAKO Cytomation, Glostrup, Denmark) were additionally applied. In brief, for demasking of the antigens, sections were treated with antigen-retrieval solution according to the recommendations of the manufacturer (DAKO); they were then blocked with $2 \%$ bovine serum albumin in phosphate-buffered saline (pH 7.4) and incubated overnight at $4{ }^{\circ} \mathrm{C}$ with rabbit IGF-I antiserum (Oberlin et al. 2009) followed by visualisation with fluorescein isothiocyanate (FITC)-coupled goat anti-rabbit IgG (Bioscience Products, Emmenbrücke, Switzerland). Subsequently, antibodies against CD3 (Abcam, UK), CD15, CD20, CD30 and CD68 (all from DAKO) were applied overnight at $4{ }^{\circ} \mathrm{C}$ and visualised with Texas-redconjugated goat anti-mouse IgGs (Bioscience and Amersham, Little Chalfont, UK). IGF-1R was detected by double-immunofluorescence with chicken anti-human IGF-1R antiserum followed by visualisation with FITC- coupled goat anti-chicken IgG (both Abcam, UK). Subsequently, the antibody against CD30 was applied overnight at $4{ }^{\circ} \mathrm{C}$ and visualised with Texas-red-conjugated goat anti-mouse IgG. Specificity of the antisera was tested by omitting the primary antisera as a negative control and by using sections of human breast cancer, intestine and lymph node and rat pancreas as positive controls as previously described (Eppler et al. 2002; Jevdjovic et al. 2004, 2005; Oberlin et al. 2009; Link et al. 2013) and an embryonic tumour known to contain CD30-immunoreactive cells.

Immunohistochemistry

Additionally, immunohistochemistry was applied by using rabbit anti-human IGF-1R antibody (Ventana, Tucson, Ariz., USA). One HL TMA section $(3.0 \mu \mathrm{m})$ was transferred to one glass slide followed by immunohistochemical analysis on an instrument according to Ventana automat protocols. Each TMA slide was pretreated with CC1 buffer (Ventana) for $64 \mathrm{~min}$ followed by incubation for $24 \mathrm{~min}$ and subsequently detection with an ultraView Universal DAB kit (Ventana).

\section{Imaging}

Conventional light and fluorescence images were photographed with a Zeiss Axioscope by using Axiovision software 3.1. (Zeiss, Zürich, Switzerland). TMA slides were scanned by using a NanoZoomer (Hamamatsu, Hamamatsu City, Japan).

\section{Results}

Immunoreactivity for IGF-I and for IGF-1R was examined in cHL and NLPHL cells of various types (Figs. 1, 2, 3, 4, 5, 6 and 7).

IGF-I immunoreactivity in cHL cells of mixed cellularity type

IGF-I immunoreactivity was detected regularly in HRS cells of cHL of mixed cellularity in all cases investigated by double-immunofluorescence for IGF-I and CD30 (Fig. 1). Additionally, IGF-I immunoreactivity was detected in endothelial cells of high endothelial venules and numerous other cells of the microenvironment surrounding the tumour (Figs. 4 and 5). In particular, neutrophils within the tumour microenvironment were identified by their immunoreactivity for $\mathrm{CD} 15$ and were shown to contain IGF-I immunoreactive material, as did tumour cells of cHL, which are also known to express CD15 
Fig. 1 Insulin-like growth factor I (IGF-I) in classical Hodgkin's lymphoma (cHL) cells of mixed cellularity type. a Haematoxylin and eosin (HE) staining (arrows Hodgkin and Reed-Sternberg [HRS] cells). Bar $80 \mu \mathrm{m}$. b-d Immunofluorescence. b CD30 immunoreactivity (red). Note CD30-immunoreactive HRS cells (arrows). c IGF-I

immunoreactivity (green). Note IGF-I-immunoreactive HRS cells (arrows) and cells immunoreactive for IGF-I (asterisks) but not immunoreactive for $\mathrm{CD} 30(\mathbf{c}, \mathbf{d})$. d Overlay of b, c (arrows CD30+ IGF-I-immunoreactive HRS cells, asterisks cells immunoreactive for IGF-I exclusively, $V$ IGF-Iimmunoreactive endothelium of high endothelial venules). Bar $50 \mu \mathrm{m}$
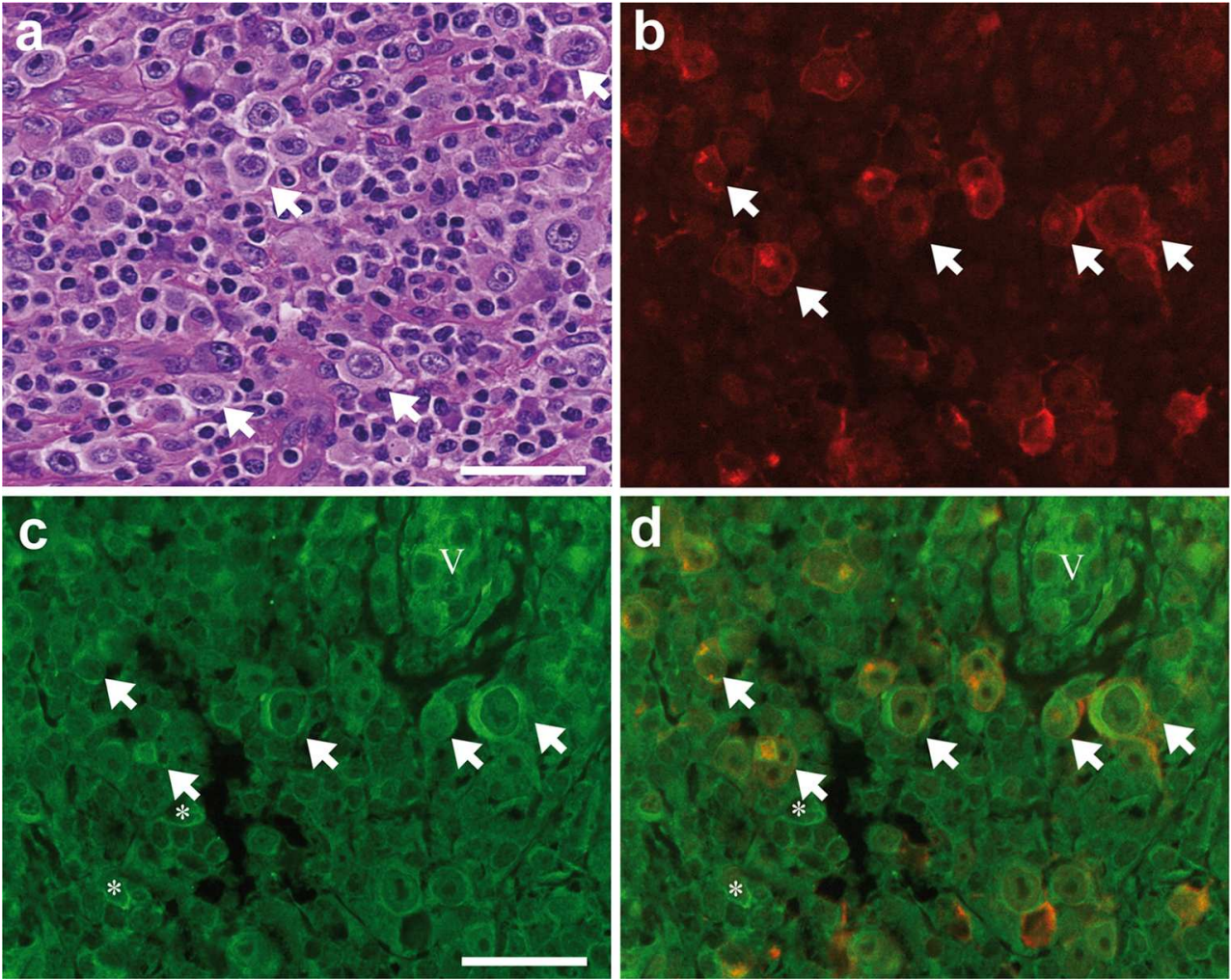

with variable intensity (Fig. 4). Furthermore, macrophages within the tumour microenvironment identified by their immunoreactivity for CD68 contained IGF-I immunoreactive material (Fig. 5), whereas CD20+ B (Fig. 7) and CD3 + T lymphocytes (data not shown) were not found to contain IGF-I immunoreactive material.
Fig. 2 IGF-I in cHL cells of nodular sclerosis type. a HE stain (arrows HRS cells). Bar $80 \mu \mathrm{m}$. b-d Immunofluorescence. b CD30 immunoreactivity (red). Note CD30-immunoreactive HRS cells (arrows). c IGF-I immunoreactivity (green). Note IGF-I-immunoreactive HRS cells (arrows) and IGF-I-

immunoreactive but CD30negative cells within the tumour microenvironment (asterisks). d Overlay of b, $\mathbf{c}$ (arrows CD30+ IGF-I-immunoreactive HRS cells, asterisks IGF-I-immunoreactive but CD30-negative cells of the tumour microenvironment). Bar $50 \mu \mathrm{m}$
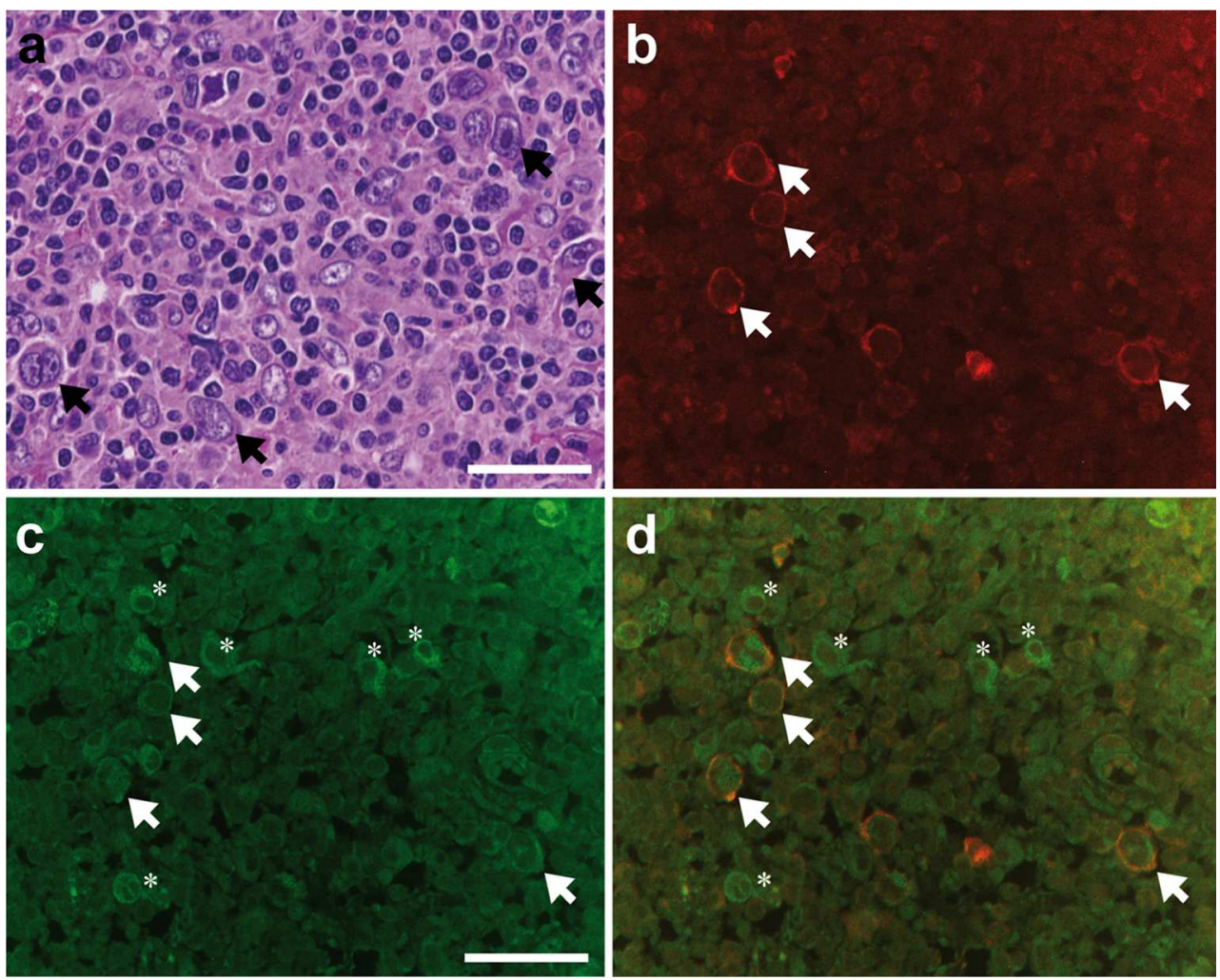
Fig. 3 IGF-I in lymphocytepredominant (LP) cells of the nodular lymphocyte-predominant type (NLPHL). a HE stain (arrows LP cells). Bar $80 \mu \mathrm{m}$. b-d Immunofluorescence. $\mathbf{b}$ CD20 immunoreactivity (red). Note CD20-immunoreactive LP cells (arrows). Numerous B cells $(B)$ in addition to the tumour LP cells are immunoreactive for CD20. Note also the reduced amount of CD20-immunoreactive cells around the LP cells; the former cells are most probably T cells $(T)$ that are sometimes arranged in a rosette-like structure. c IGF-I immunoreactivity (green). Note IGF-I-immunoreactive LP cells (arrows). d Overlay of b, c (arrows CD20+ IGF-Iimmunoreactive LP cells). Bar $50 \mu \mathrm{m}$
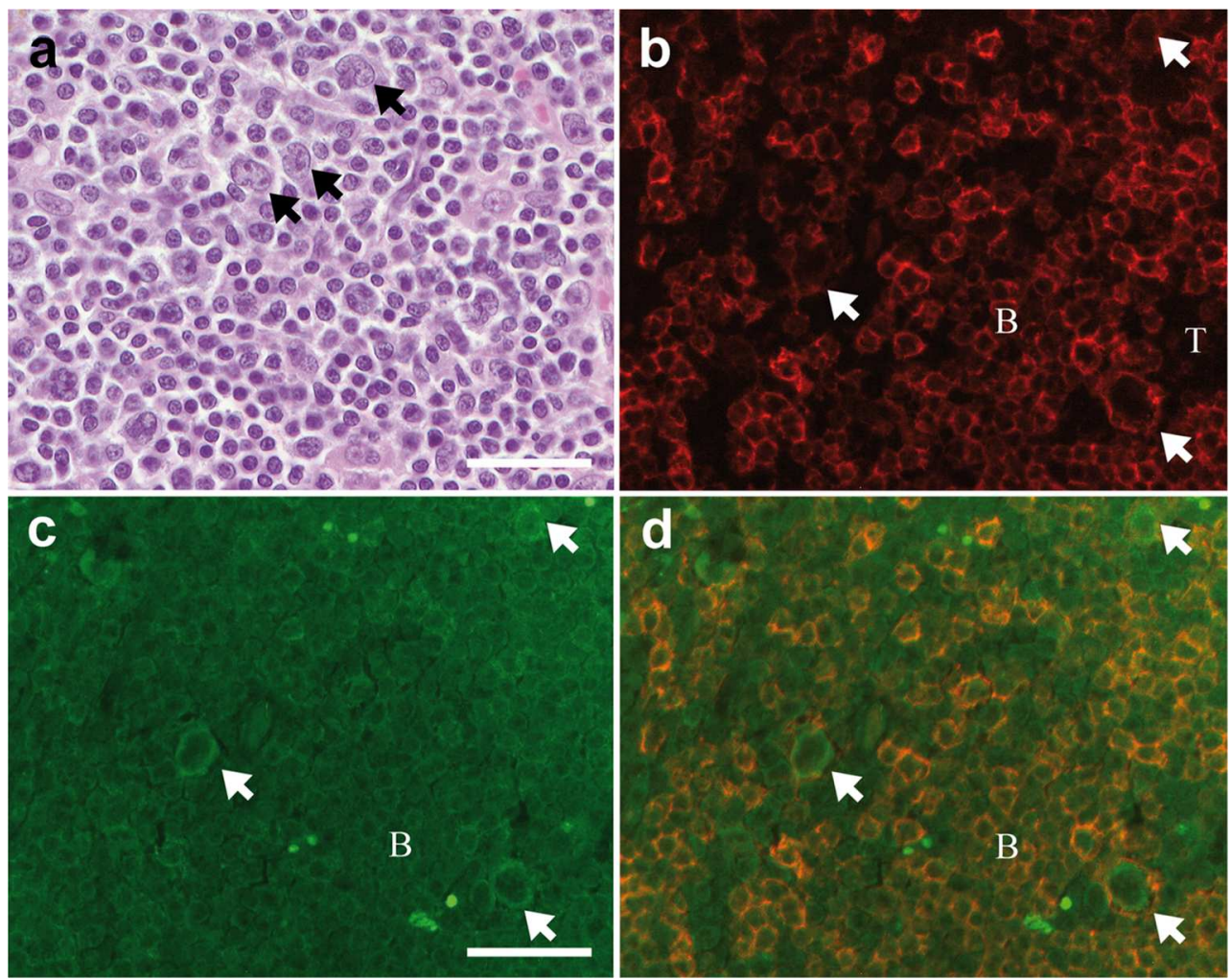

IGF-I immunoreactivity in cHL cells of nodular sclerosis type

IGF-I immunoreactivity was detected regularly in HRS cells of nodular sclerosis cHL in all cases investigated by doubleimmunofluorescence for IGF-I and CD30 (Fig. 2). As in cHL of mixed cellularity type (Figs. 1, 4 and 5), numerous other cell types of the tumour microenvironment expressed IGF-I immunoreactivity.

IGF-I immunoreactivity in LP cells of NLPHL

IGF-I immunoreactivity was detected in LP cells of NLPHL cases investigated by double-immunofluorescence for IGF-I and CD20 (Fig. 3). Furthermore, numerous CD20-negative cells of the tumour microenvironment expressed IGF-I immunoreactivity. Expectedly, numerous B cells in the microenvironment were immunoreactive for $\mathrm{CD} 20$ in addition to the LP cells. Among these, cells without immunoreactivity for CD20 could be observed around the LP cells; the former are most probably rosette-forming T cells (Fig. 3).

\section{IGF-1R immunoreactivity in cHL}

IGF-1R immunoreactivity was detected with variable intensity of expression in HRS cells of cHL identified by immunohistochemistry (Fig. 6a) and by double-immunofluorescence with CD30. In particular, high IGF-1R expression was observed in the mononuclear Hodgkin cells, whereas the inspected RS cells revealed lower IGF-1R density (Fig. 6a, $\mathrm{b}, \mathrm{d})$. Additionally, IGF-1R immunoreactivity was detected in the microenvironment, particularly in the high endothelial venules (Fig. 6c, d).

\section{Discussion}

Here, for the first time, we located IGF-I immunoreactive material intracellularly in HRS cells of mixed cellularity and the nodular sclerosis type of cHL in histopathological tissue, in LP cells of NLPHL and in distinct cells of the tumour microenvironment in general. IGF-I has been under debate as a factor involved in tumor pathogenesis for decades, with elevated circulating IGF-I levels being an increased risk factor for the development of certain cancers such as those of the colon, breast and prostate. Conversely, individuals with GH receptor deficiency exhibiting the so-called Laron syndrome of GH insensitivity and IGF-I defiency appear to be protected against cancer development (Gallagher and LeRoith 2011; Clayton et al. 2011; Dijogue et al. 2013).

IGF-I immunoreactivity has been previously observed in stroma cells and higher differentiated breast cancer cells (Eppler et al. 2002), whereas decreased IGF-I immunoreactivity has been detected in human primary liver cancer as compared with normal liver (Ikeda et al. 2013). Moreover, IGF-I mRNA and (to a lesser extent) IGF-I peptide have been 

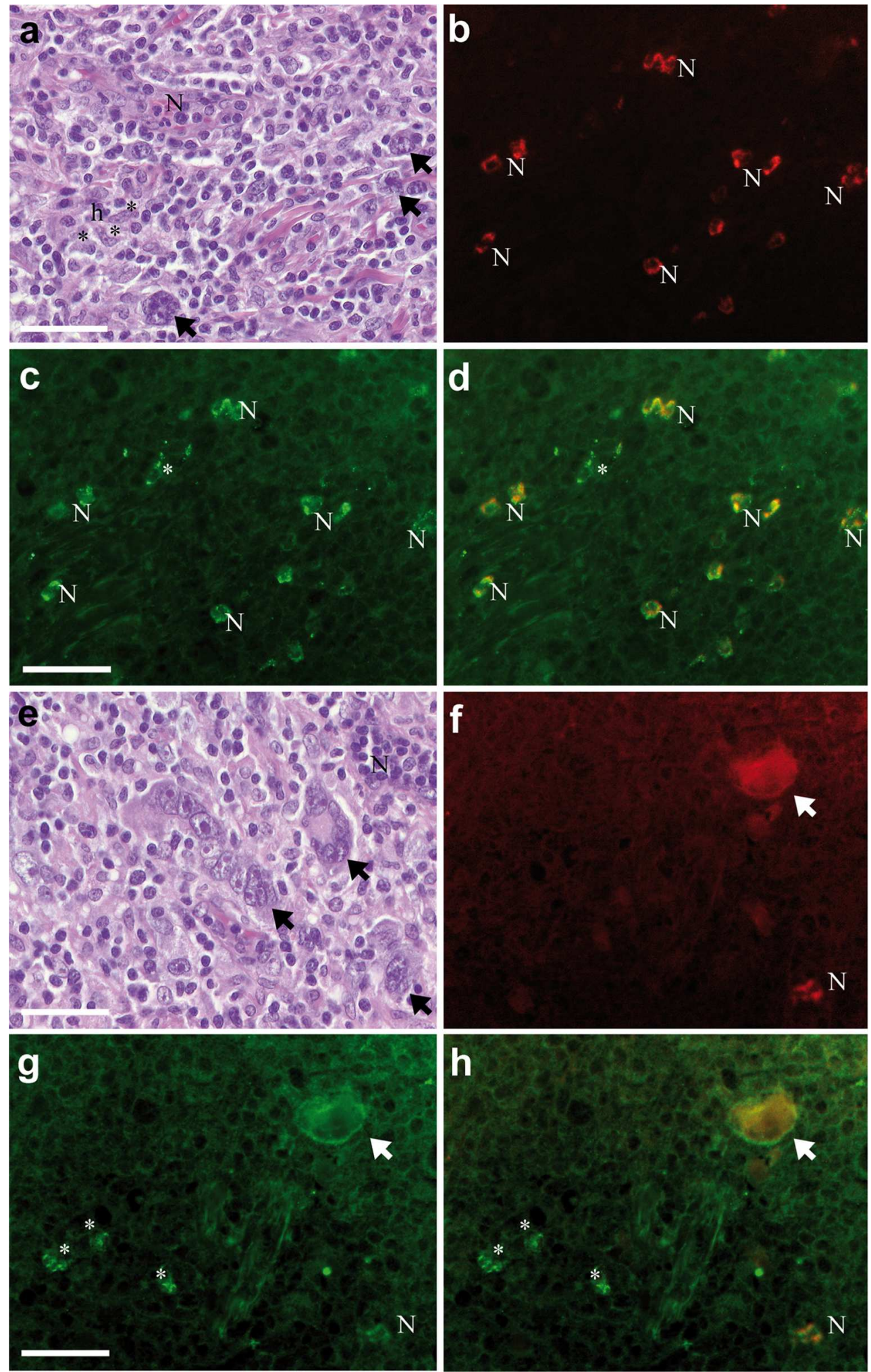

found in stroma and tumour cells of a lymph node metastasis of an IGF-I-producing tumour (Nauck et al. 2007); this supports the assumption that local autocrine/paracrine IGF-I is generally involved in the proliferation and differentiation of 
4 Fig. 4 IGF-I in CD15+ granulocytes within a tumour microenvironment of mixed cellularity cHL. a HE stain (arrows HRS cells). Note neutrophils $(N)$ within the blood vessel and histiocytes $(h)$ designated with asterisks within the microenvironment. Bar $80 \mu \mathrm{m}$. b-d Immunofluorescence. b CD15 immunoreactivity (red). Note the numerous CD15-immunoreactive neutrophils $(N)$ within the tumour microenvironment. c IGF-I immunoreactivity in cells also immunoreactive for CD15 designated as neutrophils $(N)$. Note cells immunoreactive for IGF-I (asterisks) but not immunoreactive for CD15 (c, d). d Overlay of b, c. Bar $50 \mu \mathrm{m}$. e HE stain (arrows HRS cells). Note neutrophil $(N)$ within the blood vessel. Bar $80 \mu \mathrm{m}$. f-h Immunofluorescence. f CD15 immunoreactivity (red). Note CD15immunoreactive neutrophil $(N)$ within the tumour microenvironment and HRS cell expressing CD15 (arrow). g IGF-I immunoreactivity in cells immunoreactive for CD15 and also in a cell designated as a neutrophil $(N)$. Note cells immunoreactive for IGF-I (asterisks) but not immunoreactive for CD15 (g, h). h Overlay of f, g. Bar $50 \mu \mathrm{m}$ tumour cells and in the establishment of a tumour-sustaining microenvironment.

IGF-I has been proposed generally to stimulate immune organs and cells and, in particular, B cell development and differentiation and B cell leukemia cell lines (Landreth et al. 1992; Taguchi et al. 2006); for example, it potentiated the expansion of interleukin-7 (IL-7)-dependent pro-B cells in one study (Gibson et al. 1993), whereas in another study, it failed to induce a proliferative response in childhood acute lymphoblastic leukemia-derived pre-B cell lines in combination with IL-7 (Consolini et al. 1997). Although IGF-I stimulates DNA synthesis in a Burkitt-type ALL-cell line, in an ANLL-cell line and in a Hodgkin's disease cell line (Vetter et al. 1986; Shimon and Shpilberg 1995), the antibody blocking of IGF-I or the IGF-1R reduced proliferation of human acute lymphoblastic leukemia cell lines (Baier et al.
Fig. 5 IGF-I in CD68+ macrophages within the tumour microenvironment of mixed cellularity $\mathrm{cHL}$ and non-tumoral human lymph node. a HE stain of mixed cellularity cHL (arrow HRS cell). Note histiocytes $(h)$ designated with asterisks within the microenvironment. Bar $80 \mu \mathrm{m}$. b-d Immunofluorescence of a tumour microenvironment of mixed cellularity cHL. b CD68 immunoreactivity (red). Note CD68-immunoreactive macrophages within the tumour microenvironment. c IGF-I immunoreactivity (arrows IGF-Iimmunoreactive cells also immunoreactive for CD68 in b). d Overlay of b, c. Bar $50 \mu \mathrm{m}$. e, f Immunofluorescence of nontumoral human lymph node. e IGF-I immunoreactivity in cells immunoreactive for CD68 (f) are designated with arrows. Note cells immunoreactive for IGF-I (asterisks) but not immunoreactive for CD68. Bar $50 \mu \mathrm{m}$



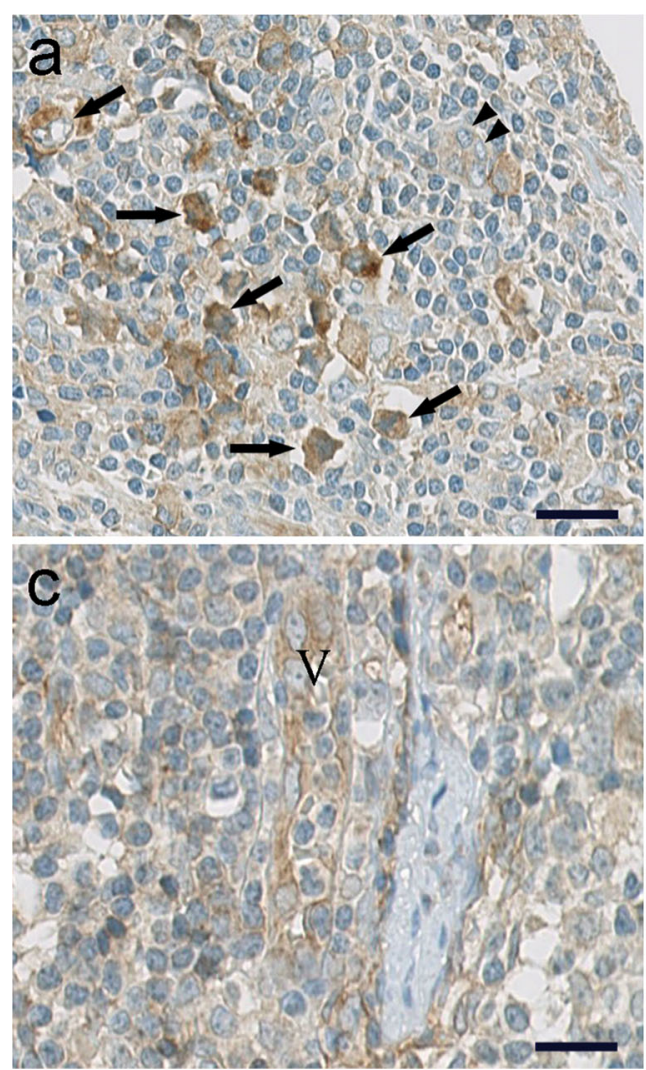

Fig. 6 IGF-I receptor (IGF-1R) in tumour cells and in the tumour microenvironment of cHL. a, c Immunohistochemistry with anti-IGF$1 \mathrm{R}$ antibody; nuclei are counterstained with haematoxylin. $\mathbf{b}, \mathbf{d}$ Doubleimmunofluorescence with anti-IGF-1R antibody (green) and CD30 (red). a Note IGF-1R-immunoreactive HRS cells (arrows) and RS cell with faint IGF-1R expression (arrowheads). Bar $60 \mu \mathrm{m}$. b Note IGF-1Rimmunoreactive HRS cells (arrows) visualised by CD30

1992). The neutralisation of IGF-I function in vitro results in a significant reduction in pro-B cell development from CD34+ cells in mice (Taguchi et al. 2006). So far, IGF-I mRNA and peptide have been found to be produced by human peripheral lymphocytes only in low amounts (Arkins et al. 1993; Kelley and Arkins 1994) or after mitogen stimulation (Nyman and Pekonen 1993). Nevertheless, most recently, IGF-I has been shown to stimulate the in vitro tumour growth of Hodgkin cell lines via the IGF-1R, which has been localised in cHL tumour cells, whereas the ligand has been detected in the cell culture supernatant (Liang et al. 2014) but remains to be localised. Thus, in the present study, we aimed at localising the ligand IGF-I in HRS cells of cHL, in the LP cells of NLPHL and in the microenvironment, which, as described above, is essential for the pathogenesis and maintenance of tumour cells and which in HL only constitute a minority of the tumour mass (Steidl et al. 2011).

In the present study, we detected IGF-I-immunoreactive material in macrophages and high endothelial venules of HL lesions, as previously described in non-tumoral lymph nodes in which we proposed a role for IGF-I in the differentiation of

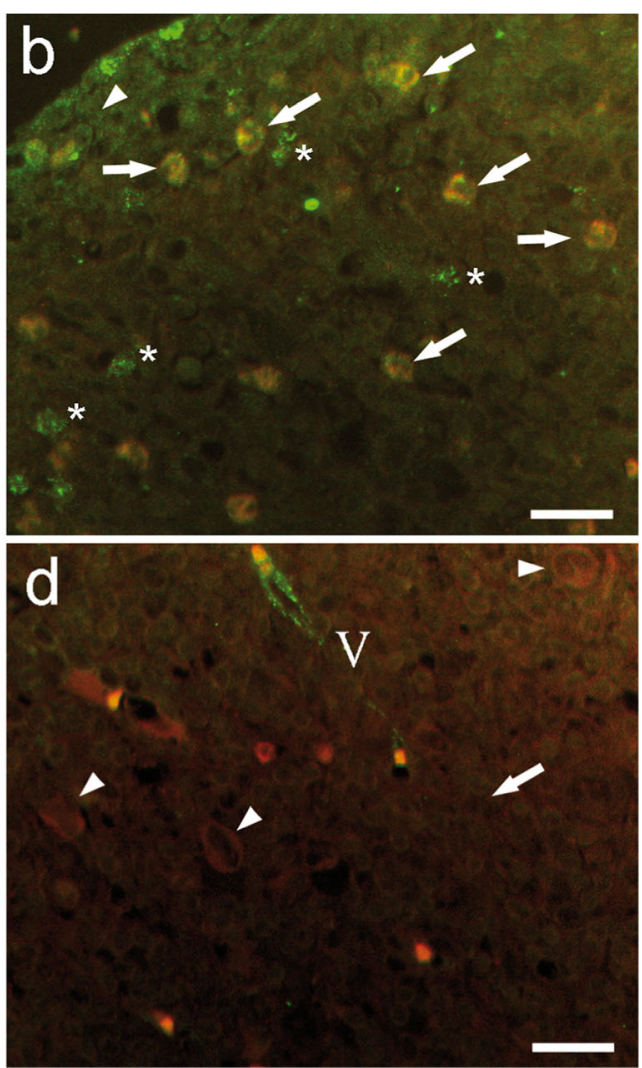

immunoreactivity (asterisks designated cells in microenvironment immunoreactive for IGF-1R exclusively). Bar $60 \mu \mathrm{m}$. c Note IGF-1Rimmunoreactive endothelium of high endothelial venules $(V)$; other blood vessels only rarely express IGF-1R. Bar $40 \mu \mathrm{m}$. d Note CD30immunoreactive HRS cells with faint IGF-1R expression (arrowheads) and IGF-1R-immunoreactive endothelium of venule $(V)$. Arrow points to sheets of non-immunoreactive cells of the microenvironment. Bar $40 \mu \mathrm{m}$

the special endothelium and attraction of lymphocytes and, particularly, in the support of macrophages during immune challenge (Oberlin et al. 2009). Thus, IGF-I might contribute to the constitution and maintenance of the tumour microenvironment, in addition to its local presence in the tumour cells themselves. The importance of local IGF-I in shaping the microenvironment is supported by the additional localisation of the IGF-1R in the endothelium of blood vessels, particularly the high endothelial venules, within the tumour microenvironment. With respect to the reported importance of the IGF-1R in endothelial function and repair under various conditions (see Imrie et al. 2012), this might be of special relevance for shaping and sustaining the microenvironment.

So far, human and murine myeloid cells, particularly macrophages, have been found to produce IGF-I, even in relatively large amounts (Arkins et al. 1993; Kelley and Arkins 1994), whereby cytokines such as TNF- $\alpha$ (Noble et al. 1993; Fournier et al. 1995) and colony-stimulating factors (Arkins et al. 1995a) have been proposed as stimulators and interferon- $\gamma$ as an inhibitor (Arkins et al. 1995b). 
Fig. 7 IGF-I in B cells within the tumour tissue of mixed cellularity cHL and non-tumoral human lymph node. a, b Doubleimmunofluorescence for CD20 (red) and IGF-I (green) in (a) tumour microenvironment of mixed cellularity $\mathrm{cHL}$ and (b) non-tumoral human lymph node. Asterisks designated cells immunoreactive for IGF-I exclusively, but not for CD20. Bar $30 \mu \mathrm{m}$. c Representation of the potential protection of transformed B cells from apoptosis by means of intracellular IGF-I. Whereas IGFI as reported in the literature has not been found in naive and nonreactive $\mathrm{B}$ cells, it has been detected after various stimuli such as Epstein-Barr virus $(E B V)$ infection and mitogenic stimulation and is involved in B cell differentiation, expansion and survival. Note the observed higher density of the IGF-1R in the present study in the mononuclear Hodgkin cells as compared with the multinuclear RS cells
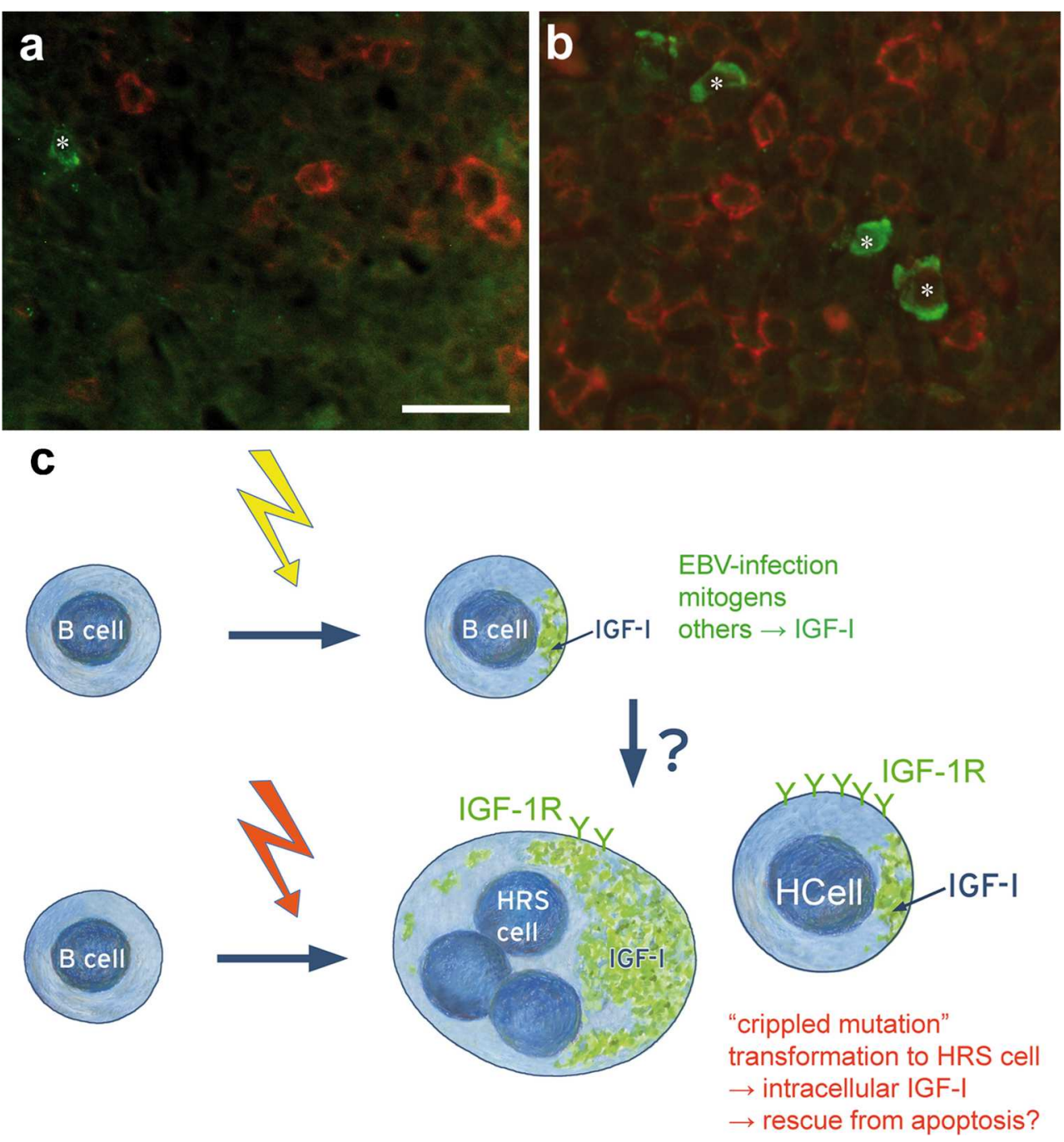

Interestingly, IGF-I has been reported to be "unexpectedly" stimulated by IL-24, a mediator of apoptosis in human B cells and activated $\mathrm{B}$ cells express the IGF-1R and undergo apoptosis (Hadife et al. 2013); this could be of particular significance in light of the recent finding that patients expressing the IGF-1R on cHL tumour cells demonstrate a better clinical outcome (Liang et al. 2014). Nevertheless, in the same study, IGF-I has been shown to stimulate tumour cell growth in vitro (Liang et al. 2014), whereas IGF-I and its receptor are upregulated by B cells undergoing apoptosis (Hadife et al. 2013).

In the present study, although the CD20+ tumour LP cells expressed IGF-I (Fig. 3), we did not detect IGF-I peptide within CD20+ B cells of the tumour microenvironment (Fig. 7a) or in CD3+ T lymphocytes (data not shown). The absence of IGF-I in lymphocytes of the human lymph node is similar to our previous findings in $\mathrm{CD} 3+\mathrm{T}$ lymphocytes and $\mathrm{CD} 20+\mathrm{B}$ lymphocytes in the non-malignant lymph node (Oberlin et al. 2009; present study). The absence of IGF-I in non-reactive B cells in our study is also in accordance with observations by other groups that freshly isolated B lymphocytes do not secrete IGF-I in vitro (Merrimee et al. 1989). Interestingly, B lymphocytes transformed by Epstein-Barr virus secrete IGF-I in vitro (Merrimee et al. 1989) and human B cell line IM-9 lymphocytes express IGF-I mRNA (Clayton et al. 1994). These observations lead to the assumption of a specific role for IGF-I in transformed B cells, which constitute the basis for HL pathogenesis as outlined above. This role is now strongly supported by our present detection of the frequent IGF-I presence in tumour cells of cHL and NLPHL, whereas some cells showing the morphology of activated CD20+ B lymphocytes (Fig. 7b) contain IGF-Iimmunoreactive material, thus exhibiting a transition form. Hence, we propose a role of IGF-I, after the activation of B cells, in the prevention of apoptosis following the crippled mutation and thus a role in the transition from transformed B cells to HL tumour cells (Fig. 7c).

Despite the small number of tumour cells in the TMA investigated, the differential degree in the expression of IGF- 
I and the IGF-1R, with stronger expression of the IGF-1R in the mononuclear Hodgkin than in the RS cells, should foster future studies. This is particularly pertinent because the enigmatic origin of the multinuclear RS cells has recently been illuminated by the findings that they arise by the re-fusion of daughter cells from small mononuclear Hodgkin cells that have undergone mitosis and constitute the proliferative compartment of the cHL tumour clone (Rengstl et al. 2013).

Acknowledgments We gratefully acknowledge the helpful support of Martina Storz (Tissue Biobank) and André Fitsche (In situ Laboratory, Institute of Surgical Pathology, Zurich University Hospital). We further thank Charlotte Burger and Heinz Sonderegger (Institute of Anatomy, University of Zurich) and Regine Göhrt (Institute of Pathology, HegauBodensee Clinic Singen) for skilful technical assistance.

\section{References}

Arkins S, Rebeiz N, Biragyn A, Reese DL, Kelley KW (1993) Murine macrophages express abundant insulin-like growth factor-I class I $\mathrm{Ea}$ and Eb transcripts. Endocrinology 133:2334-2343

Arkins S, Rebeiz N, Brunke-Reese DL, Minshall C, Kelley KW (1995a) The colony-stimulating factors induce expression of insulin-like growth factor-I messenger ribonucleic acid during hematopoesis. Endocrinology 136:1153-1160

Arkins S, Rebeiz N, Brunke-Reese DL, Minshall C, Biragyn A, Kelley KW (1995b) Interferon-gamma inhibits macrophage insulin-like growth factor-I synthesis at the transcriptional level. Mol Endocrinol 9:350-360

Avila-Gomez IC, Velez-Pardo C, Jimenez-Del-Rio M (2009) Effects of insulin-like growth factor-I on rotenone-induced apoptosis in human lymphocyte cells. Basic Clin Pharmacol Toxicol 106:53-61

Baier TG, Jenne EW, Blum W, Schönberg D, Hartmann KK (1992) Influence of antibodies against IGF-I, insulin or their receptors on proliferation of human acute lymphoblastic leukemia cell lines. Leuk Res 16:807-814

Benz AH, Renné C, Maronde E, Koch M, Grabiec U, Kallendrusch S, Rengstl B, Newrzela S, Hartmann S, Hansmann ML, Dehghani F (2013) Expression and functional relevance of cannabinoid receptor 1 in Hodgkin lymphoma. PLoS One 8:e81675

Butsch R, Waelti SL, Schaerer S, Braun J, Korol D, Probst-Hensch N, Moch H, Kurrer M (2011) Intratumoral plasmacytoid dendritic cells associate with increased survival in patients with follicular lymphoma. Leuk Lymphoma 52:1230-1238

Chetaille B, Bertucci F, Finetti P, Esterni B, Stamatoullas A, Piquenot JM, Copin MC, Morschhauser F, Casanovas O, Petrella T, Molina T, Vekhoff A, Feugier P, Bouabdallah R, Birnbaum D, Olive D, Xerr L (2009) Molecular profiling of classical Hodgkin lymphoma tissues uncovers variations in the tumor microenvironment and correlations with EBV infection and outcome. Blood 113:2765-3775

Clayton PE, Day RN, Silva CM, Hellmann P, Day KH, Thorner MO (1994) Growth hormone induces tyrosine phosphorylation but does not alter insulin-like growth factor-I gene expression in human IM9 lymphocytes. J Mol Endocrinol 13:127-136

Clayton PE, Banerjee I, Murray PG, Renehan AG (2011) Growth hormone, the insulin-like growth factor axis, insulin and cancer risk. Nat Rev Endocrinol 7:11-24

Consolini R, Legitimo A, Cattani M, Simi P, Mattii L, Petrini M, Putti C, Basso G (1997) The effect of cytokines, including IL4, IL7, stem cell factor, insulin-like growth factor on childhood acute lymphoblastic leukaemia. Leuk Res 21:753-761
Dijogue S, Kamdje AHN, Vecchio L, Kipanyula MJ, Farahna M, Aldebasi Y, Etet PFS (2013) Insulin resistance and cancer: the role of insulin and IGFs. Endocr Relat Cancer 20:R1-R17

Eppler E, Zapf J, Bailer N, Falkmer UG, Falkmer S, Reinecke M (2002) IGF-I in human breast cancer: low differentiation stage is associated with decreased IGF-I content. Eur J Endocrinol 146:813-821

Farrell K, Jarrett RF (2011) The molecular pathogenesis of Hodgkin lymphoma. Histopathology 58:15-25

Fournier T, Riches DW, Winston BW, Rose DM, Young SK, Noble PW, Lake FR, Henson PM (1995) Divergence in macrophage insulinlike growth factor-I (IGF-I) synthesis induced by TNF-alpha and prostaglandin E2. J Immunol 155:2123-2133

Gallagher EJ, LeRoith D (2011) Minireview: IGF, insulin, and cancer. Endocrinology 152:1-6

Gao L, Wang X, Wang X, Zhang L, Qiang C, Chang S, Ren W, Li S, Yang Y, Tong D, Chen C, Li Z, Song T, Zhi K, Huang C (2014) IGF-1R, a target of let-7b, mediates crosstalk between IRS-2/Akt and MAPK pathways to promote proliferation of oral squamous cell carcinoma. Oncotarget 5:2562-2574

Gibson LF, Piktel D, Landreth KS (1993) Insulin-like growth factor-1 potentiates expansion of interleukin-7-dependent pro-B cells. Blood 82:3006-3011

Hadife N, Nemos C, Frippiat JP, Hamadé T, Perrot A, Dalloul A (2013) Interleukin-24 mediates apoptosis in human B-cells through early activation of cell cycle arrest followed by late induction of the mitochondrial apoptosis pathway. Leuk Lymphoma 54:587-597

Ikeda Y, Kajiyama K, Yamashita Y, Ikegami T, Uchiyama H, Soejima Y, Kawanaka H, Ikeda T, Morita M, Oki E, Saeki H, Suehiro T, Mimori K, Sugimachi K, Shirabe K, Maehara Y (2013) Differential expression of insulin-like growth factor 1 in human primary liver cancer. Fukuoka Soc Zasshi 104:334-338

Imrie H, Viswambharan H, Sukumar P, Abbas A, Cubbon RM, Yuldasheva N, Gage M, Smith J, Galloway S, Skromna A, Rashid ST, Futers TS, Xuan S, Gatenby VK, Grant PJ, Channon KM, Beech DJ, Wheatcroft SB, Kearney MT (2012) Novel role of the IGF-1 receptor in endothelial function and repair: studies in endotheliumtargeted IGF-1 receptor transgenic mice. Diabetes 61:2359-2368

Jevdjovic T, Maake C, Eppler E, Zoidis E, Reinecke M, Zapf J (2004) Effects of insulin-like growth factor-I treatment on the endocrine pancreas of hypophysectomized rats: comparison with growth hormone replacement. Eur J Endocrinol 151:223-231

Jevdjovic T, Maake C, Zwimpfer C, Krey G, Eppler E, Zapf J, Reinecke M (2005) The effect of hypophysectomy on pancreatic islet hormone and insulin-like growth factor I content and mRNA expression in rat. Histochem Cell Biol 123:179-188

Kanzler H, Küppers R, Hansmann ML, Rajewski K (1996) Hodgkin and Reed-Sternberg cells in Hodgkin's disease represent the outgrowth of a dominant tumor clone derived from (crippled) germinal center B cells. J Exp Med 184:1495-1505

Kelley KW, Arkins S (1994) A role for IGF-1 during myeloid cell growth and differentiation. In: Baxter RC, Gluckman PD, Psenfeld RG (eds) The role for insulin-like growth factors and regulatory proteins. Elsevier, Amsterdam, pp 315-327

Küppers R (2009) The biology of Hodgkin's lymphoma. Nat Rev Cancer 9:15-27

Küppers R, Engert A, Hansmann ML (2011) Hodgkin lymphoma. J Clin Invest 122:3439-3447

Landreth KS, Narayanan R, Dorshkind K (1992) Insulin-like growth factor-I regulates pro-B-cell differentiation. Blood 80:12071212

Liang Z, Diepstra A, Xu C, Imhoff G van, Plattel W, Van den Berg A, Visser L (2014) Insulin-like growth factor 1 receptor is a prognostic factor in classical Hodgkin lymphoma. PLoS One 9:e87474

Link KR, Allio I, Rand JS, Eppler E (2013)The effect of experimentally induced chronic hyperglycaemia on serum and pancreatic insulin, pancreatic islet IGF-I and plasma and urinary 
ketones in the domestic cat (Felis felis). Gen Comp Endocrinol 188:269-281

Merrimee TJ, Grant MB, Broder CM, Cavalli-Sforza LL (1989) Insulinlike growth factor secretion by human B-lymphocytes: a comparison of cells from normal and pygmy subjects. Clin Endocrinol Metab 69:978-984

Nauck MA, Reinecke M, Perren A, Frystyk J, Berishvili G, Zwimpfer C, Figge AM, Flyvberg A, Lankisch PG, Blum WF, Klöppel G, Schmiegel W, Zapf J (2007) Hypoglycemia due to paraneoplastic secretion of insulin-like growth factor-I in a patient with metastasizing large-cell carcinoma of the lung. J Clin Endocrinol Metab 92: $1600-1605$

Noble PW, Lake FR, Henson PM, Riches DWH (1993) Hyaluronate activation of CD44 induces insulin-like gowth factor-1 expression by a tumor necrosis factor-alpha dependent mechanism in murine macrophages. J Clin Invest 91:2368-2377

Nyman T, Pekonen F (1993) The expression of insulin-like growth factors and their binding proteins in normal human lymphocytes. Acta Endocrinol (Copenh) 128:168-172

Oberlin D, Fellbaum C, Eppler E (2009) Insulin-like growth factor I messenger RNA and protein are expressed in the human lymph node and distinctly confined to subtypes of macrophages, antigenpresenting cells, lymphocytes and endothelial cells. Immunology $128: 342-350$

Okusaka T, Ikeda M, Fukutomi A, Kobayashi Y, Shibayama K, Takubo T, Gansert J (2014) Safety, tolerability, pharmacokinetics and antitumor activity of ganitumab, an investigational fully human monoclonal antibody to insulin-like growth factor type 1 receptor, combined with gemcitabine as first-line therapy in patients with metastatic pancreatic cancer: a phase 1b study. Jpn J Clin Oncol 44:442-447

Pollak M (2009) Insulin and insulin-like growth factor signaling in neoplasia. Nat Rev Cancer 8:915-928

Rengstl B, Newrzela S, Heinrich T, Weiser C, Thalheimer FB, Schmid F, Warner K, Hartmann S, Schroeder T, Küppers R, Rieger MA, Hansmann ML (2013) Incomplete cytokinesis and re-fusion of small mononucleated Hodgkin cells lead to giant multinucleated Reed-Sternberg cells. Proc Natl Acad Sci U S A 110:20729-20734

Renné C, Willenbrock K, Küppers R, Hansmann ML, Bräuninger A (2005) Autocrine- and paracrine-activated receptor tyrosine kinases in classic Hodgkin lymphoma. Blood 105:4051-4059

Renné C, Hansmann ML, Bräuninger A (2009) Receptor-tyrosinkinases in Hodgkin-lymphomas. Pathologe 30:393-400

Roman E, Smith AG (2011) Epidemiology of lymphomas. Histopathology 58:4-14

Schmitz R, Stanelle J, Hansmann ML, Küppers R (2009) Pathogenesis of classical and lymphocyte-predominant Hodgkin lymphoma. Annu Rev Pathol Mech Dis 4:151-174
Schwering I, Bräuninger A, Klein U, Jungnickel B, Tinguely M, Diehl V, Hansmann ML, Dalla-Favera R, Rajewski K, Küppers R (2003) Loss of the B-lineage-specific gene expression program in Hodgkin and Reed-Sternberg cells of Hodgkin lymphoma. Blood 101:1505-1512

Shimon I, Shpilberg O (1995) The insulin-like growth factor system in regulation of normal and malignant hematopiesis. Leuk Res 19:233240

Soldini D, Montagna C, Schüffler P, Martin V, Georgis A, Thiesler T, Curioni-Fontecedro A, Went P, Bosshard G, Dehler S, Mazzachelli L, Tinguely M (2013) A new diagnostic algorithm for Burkitt and diffuse large B-cell lymphomas based on the expression of CSE1L and STAT3 and on MYC rearrangement predicts outcome. Ann Oncol 24:193-201

Steidl C, Connors JM, Gascoyne RD (2011) Molecular pathogenesis of Hodgkin's lymphoma: increasing evidence of the importance of the microenvironment. J Clin Oncol 29:1812-1826

Steimle-Grauer SA, Tinguely M, Seada L, Fellbaum C, Hansmann ML (2003) Expression patterns of transcription factors in progressively transformed germinal centers and Hodgkin lymphoma. Virchows Arch 442:284-293

Steu S, Baucamp M, Dach G von, Bawohl M, Dettwiler S, Storz M, Moch H, Schraml P (2008) A procedure for tissue freezing and processing applicable to both intra-operative frozwn section diagnosis and tissue banking in surgical pathology. Virchows Arch 452: 305-312

Swerdlow SH, Campo E, Harris NL, Jaffe ES, Pileri SA, Stein H, Thiele J, Vardiman JW (2008) WHO classification of tumours of haematopoietic and lymphoid tissues, 4th edn. WHO classification of tumours, vol 2. International Agency for Research on Cancer (IARC), Lyon

Taguchi T, Takenouchi H, Matsui J, Tang WR, Itagaki M, Shiozawa Y, Suzuki K, Sakaguchi S, Ktagiri YU, Takahashi T, Okita H, Fujimoto J, Kiyokawa N (2006) Involvement of insulin-like growth factor-I and insulin-like growth factor binding proteins in pro-B-cell development. Exp Hematol 34:508-518

Taslipinar A, Bolu E, Kebapcilar L, Sahin M, Uckaya G, Kutlu M (2009) Insulin-like growth factor-1 is essential to the increased mortality caused by excess growth hormone: a case of thyroid cancer and nonHodgkin's lymphoma in a patient with pituitary acromegaly. Med Oncol 26:62-66

Vetter U, Schlickenrieder JHM, Zapf J, Hartmann W, Heit W, Hitzler H, Byrne P, Gaedicke G, Heinze E, Teller WM (1986) Human leukemic cells: receptor binding and biological effects of insulin and insulinlike growth factors. Leuk Res 19:1201-1207

Von Teichman A, Storz M, Dettwiler S, Moch H, Schraml P (2012) Whole genome and transcriptome amplification: practicable tools for sustainable tissue biobanking? Virchows Arch 461:571-580 